\title{
Multisystem inflammatory syndrome in adults (MIS-A) following COVID-19 requiring venoarterial extracorporeal membrane oxygenation
}

\author{
Seth Newman, ${ }^{1}$ Fengwei Zou, ${ }^{1}$ Shivank Madan, ${ }^{2}$ Daniel Sims ${ }^{2}$
}

\begin{abstract}
'Department of Medicine, Montefiore Medical Center, Bronx, NY, USA

${ }^{2}$ Division of Cardiology, Department of Medicine, Montefiore Medical Center, Bronx, NY, USA
\end{abstract}

Correspondence to Dr Daniel Sims: dsims@montefiore.org

Accepted 24 February 2022

Check for updates

(c) BMJ Publishing Group Limited 2022. No commercial re-use. See rights and permissions. Published by BMJ.

To cite: Newman S, Zou F, Madan $S$, et al. BMJ Case Rep 2022;15:e247427 doi:10.1136/bcr-2021247427

\section{SUMMARY}

The SARS-CoV-2 virus has caused a global pandemic with serious impact around the world. Patients most commonly present with severe lung involvement and acute respiratory failure; however, multisystem inflammatory syndrome in adults (MIS-A) is a known —although rare - complication. We present a case of a 49-year-old patient who presented with combined cardiogenic and vasodilatory shock and was diagnosed with MIS-A. He initially required venoarterial extracorporeal membrane oxygenation and Impella for haemodynamic support but was able to be weaned off these devices with complete recovery of left ventricular systolic function. This case demonstrates that MIS-A may present as haemodynamic collapse in adults, but complete recovery is possible with proper haemodynamic support.

\section{BACKGROUND}

The COVID-19 pandemic has caused serious illness around the world with acute respiratory failure being the most common complication. ${ }^{1}$ However, around April 2020, clinicians noticed a new entity called multisystem inflammatory syndrome in children (MISC). ${ }^{2}$ This presented as cardiovascular shock, fever and hyperinflammation. Since then, similar cases have been described in adults (called multisystem inflammatory syndrome in adults (MIS-A)), but the prognosis and management strategies are still unknown. We present a case of an adult with MIS-A who presented with combined cardiogenic and vasodilatory shock requiring venoarterial extracorporeal membrane oxygenation (VA-ECMO) and Impella for haemodynamic support. ${ }^{3}$

\section{CASE PRESENTATION}

A man in his 40 s with a medical history of hypertension presented with 2 weeks of cough, dyspnoea on exertion and intermittent fevers $\left(\mathrm{T}_{\max }: 102^{\circ} \mathrm{F}\right)$. Vital signs on presentation were blood pressure $106 / 70 \mathrm{~mm} \mathrm{Hg}$, heart rate 130 beats/min, respiratory rate 17 breaths $/ \mathrm{min}$, temperature $97.7^{\circ} \mathrm{F}$ $\left(36.5^{\circ} \mathrm{C}\right)$ and oxygen saturation $95 \%$ on room air. He did not have chest pain, palpitations, dizziness or contacts with a known acute illness.

\section{INVESTIGATIONS}

Initial laboratory values were suggestive of inflammation and significant end-organ dysfunction, including creatinine $3.0 \mathrm{mg} / \mathrm{dL}$ (normal: $0.7-1.3 \mathrm{mg}$ $\mathrm{dL}$ ), white blood cell count $19.6 \times 10^{9} / \mathrm{L}$ (normal: $\left.5-10 \times 10^{9} / \mathrm{L}\right)$ and venous lactic acid $5.1 \mathrm{mmol} / \mathrm{L}$ (normal: $0.5-2.2 \mathrm{mmol} / \mathrm{L}$ ). SARS-CoV-2 nasal swab was negative. His initial chest X-ray was unremarkable. ECG showed $1 \mathrm{~mm}$ ST-segment depressions in leads II, III and aVF.

Soon after admission, the patient became diaphoretic and dyspnoeic. Repeat vital signs showed blood pressure 90/50 $\mathrm{mm} \mathrm{Hg}$ and sinus tachycardia 120 beats/min. Transthoracic echocardiogram (TTE) showed diffuse left ventricular hypokinesis with a left ventricular ejection fraction of $10 \%$, mild LV dilatation (left ventricular internal dimenstion in diastole $5.8 \mathrm{~cm}$ ) and severe right ventricular hypokinesis consistent with new-onset biventricular heart failure (figure 1A,B). Inflammatory markers were significantly elevated, including $\mathrm{C}$ reactive protein $39.3 \mathrm{mg} / \mathrm{dL}$, D-dimer $3.62 \mathrm{ug} / \mathrm{mL}$, ferritin $3119.5 \mathrm{ng} / \mathrm{mL}$ and lactic dehydrogenase $483 \mathrm{U} / \mathrm{L}$ (figure 2).

Due to concern for cardiogenic shock, he was started on continuous infusions of dobutamine, epinephrine and vasopressin. However, he remained hypotensive despite escalating dosages. A pulmonary artery catheter was inserted and was consistent with combined cardiogenic and vasodilatory shock (mean arterial pressure $65 \mathrm{~mm} \mathrm{Hg}$, right atrial pressure $15 \mathrm{~mm} \mathrm{Hg}$, pulmonary artery pressure $32 / 20 \mathrm{~mm} \mathrm{Hg}$ (mean $25 \mathrm{~mm} \mathrm{Hg}$ ), pulmonary capillary wedge pressure $21 \mathrm{~mm} \mathrm{Hg}$, pulmonary artery saturation $27.4 \%$, Fick cardiac output $3.7 \mathrm{~L} / \mathrm{min}$, Fick cardiac index $1.9 \mathrm{~L} / \mathrm{min} / \mathrm{m}^{2}$ and systemic vascular resistance 1081 dynes $/ \mathrm{sec} / \mathrm{cm}^{5}$ ). The patient underwent VA-ECMO placement.

The patient developed worsening hypoxaemic respiratory failure and pulmonary oedema on chest X-ray due to his inability to unload his left ventricle. There was minimal aortic pulsatility and pulmonary capillary wedge pressure was increased. As a result, he underwent Impella cardiac power placement. This is a percutaneous device that is placed across the aortic valve and pulls blood from the left ventricle into the aorta.

\section{DIFFERENTIAL DIAGNOSIS}

Due to concern for fulminant myocarditis, the infectious disease service was consulted. Blood cultures were negative. Infectious serologies, including hepatitis B, hepatitis C, parvovirus B19, Cytomegalovirus, Epstein-Barr virus, Lyme and Rickettsia, were negative. However, SARS-CoV-2 immunoglobulin G ( $\operatorname{IgG}$ ) nucleocapsid antibody was positive. The patient underwent endomyocardial biopsy that showed occasional neutrophils and rare eosinophils consistent with catecholamine 

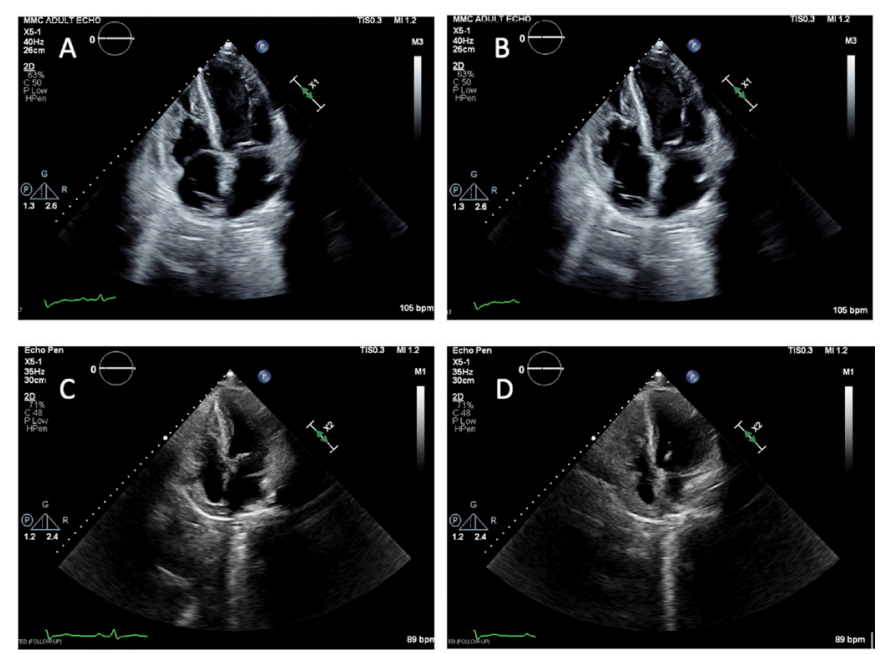

Figure 1 Initial TTE showing biventricular failure and follow-up TTE showing biventricular recovery. Panel (A) shows the initial TTE during systole. Panel (B) shows the initial TTE during diastole. Calculations showed an LVEF of $10 \%$, mild LV dilatation (left ventricular internal dimension in diastole $5.8 \mathrm{~cm}$ ) and severe right ventricular hypokinesis consistent with new-onset biventricular heart failure. Panel (C) shows the follow-up TTE at the end of systole. Panel (D) shows the followup TTE at the end of diastole. Calculations showed an LVEF of $60 \%$ consistent with recovery of left ventricular systolic function. LVEF, left ventricular ejection fraction; TTE, transthoracic echocardiogram.

injury (figure 3). Given his positive SARS-CoV-2 antibodies, lack of other infectious aetiologies and no evidence of myocarditis on endomyocardial biopsy, the diagnosis was MIS-A.

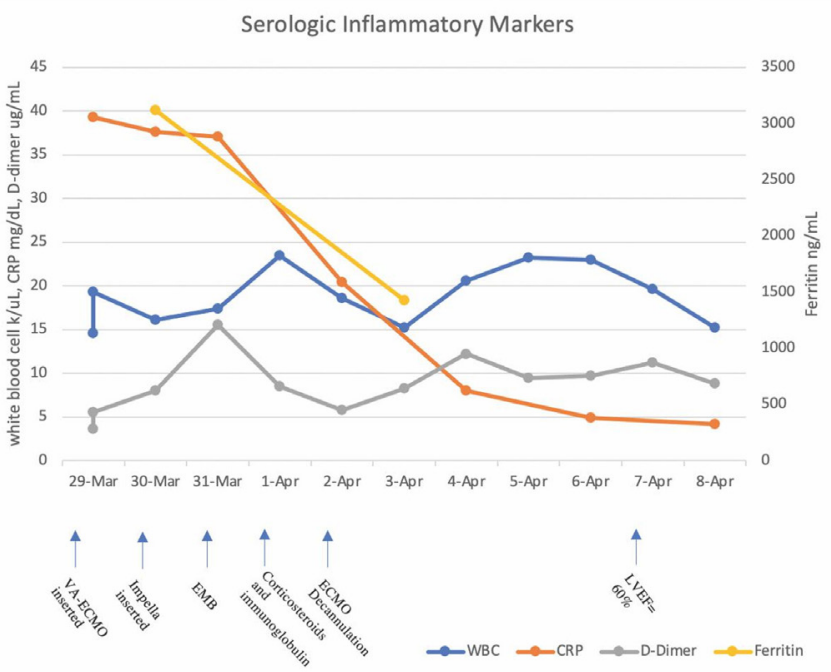

Figure 2 Graph showing a decrease in inflammatory markers. Initial inflammatory markers were elevated at the time of VA-ECMO insertion. These markers decreased during the time of corticosteroid and intravenous Ig administration and were significantly decreased at the time of VA-ECMO decannulation compared with prior. CRP, $C$ reactive protein; EMB, endomyocardial biopsy; Ig, immunoglobulin; LVEF, left ventricular ejection fraction; VA-ECMO, venoarterial extracorporeal membrane oxygenation; WBC, white blood cells.

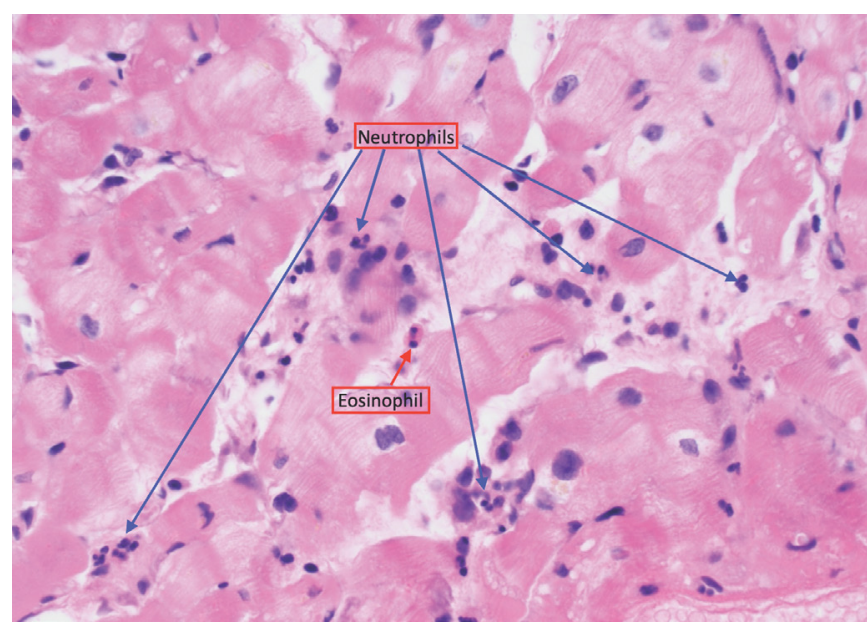

Figure 3 EMB with catecholamine-induced myocardial injury. On day 3 of hospital admission, the patient underwent EMB. Blue arrows indicate neutrophils and red arrow indicates an eosinophil. The EMB was consistent with catecholamine-induced myocardial injury. EMB, endomyocardial biopsy.

\section{TREATMENT}

The patient received one dose of intravenous methylprednisolone and one dose of intravenous Ig. These were discontinued once the endomyocardial biopsy was reported. He received dobutamine and vasopressin infusions in addition to VA-ECMO and Impella for haemodynamic support.

\section{OUTCOME AND FOLLOW-UP}

By day 5 of admission, his haemodynamics had normalised, and he underwent successful VA-ECMO decannulation. On day 6, the Impella was removed. On day 10, he underwent repeat TTE that showed complete normalisation of biventricular function (figure 1C,D). He was discharged on day 11 with heart failure and infectious disease follow-up.

\section{DISCUSSION}

MIS-A is a rare manifestation of the SARS-CoV-2 infection and is often associated with serious outcomes. ${ }^{1}$ It was first observed in children and adolescents and has been reported to have a close resemblance to Kawasaki syndrome. ${ }^{1}$ Shortly after the identification of MIS-C, several similar cases in adults were reported. The Centers for Disease Control published diagnostic guidelines on reporting MIS-A. ${ }^{2}$ Our patient met Centers for Disease Control criteria for MIS-A (table 1), namely, severe illness requiring hospitalisation, over 21 years of age, negative SARSCoV-2 PCR, severe dysfunction of one or more extrapulmonary organ system, elevated inflammatory markers and the absence of severe respiratory illness. ${ }^{24}$

MIS-A from SARS-CoV-2 infection often presents as multiorgan failure involving the heart, kidneys, liver and skin. ${ }^{5} 6$ Cardiac dysfunction can progress to haemodynamic collapse from cardiogenic shock. ${ }^{5}$ However, with proper circulatory support, left ventricle systolic function can improve dramatically. To date, only a few cases of VA-ECMO use in patients with MIS-A from COVID-19 infection have been reported. ${ }^{7-9}$ Our study reports one of the oldest patients with MIS-A treated with both Impella and VA-ECMO and indicates that even on the severe spectrum of the disease, prognosis can be good.

The pathogenesis of MIS-A is currently unclear. An abnormal inflammatory response is proposed as one of its aetiologies. ${ }^{10}$ 
Table 1 Definition of MIS-A as per $\mathrm{CDC}^{4}$

\begin{tabular}{|c|c|c|}
\hline Case definition for MIS-A & Clinical criteria & Laboratory evidence \\
\hline \multirow[t]{9}{*}{$\begin{array}{l}\text { The patient must be }>21 \text { years of age. Additionally, } \\
\text { they must be hospitalised for }>24 \text { hours or have an } \\
\text { illness resulting in death that meets the following } \\
\text { criteria }\end{array}$} & $\begin{array}{l}\text { Subjective or objective fever }\left(\geq 38.0^{\circ} \mathrm{C} \text { ) for } \geq 24 \text { prior to hospitalisation }\right. \\
\text { or within the first } 3^{*} \text { days of hospitalisation. Additionally, } 3 \text { of the } \\
\text { following clinical criteria must be met prior to hospitalisation or } \\
\text { within } 3^{*} \text { days of hospitalisation. One must be a primary clinical } \\
\text { criterion }\end{array}$ & $\begin{array}{l}\text { Laboratory evidence of inflammation and SARS- } \\
\text { CoV-2 infection }\end{array}$ \\
\hline & Primary clinical criteria & $\begin{array}{l}\text { 1. Elevation of } \geq 2 \text { of the following: erythrocyte } \\
\text { sedimentation rate, procalcitonin, ferritin, IL-6 or CRP }\end{array}$ \\
\hline & $\begin{array}{l}\text { 1. Severe cardiac illness including new-onset right or left ventricular } \\
\text { dysfunction (LVEF }<50 \% \text { ), ventricular tachycardia, second or third } \\
\text { degree A-V block, myocarditis, pericarditis or coronary artery } \\
\text { aneurysm. Cardiac arrest alone does not meet this criterion }\end{array}$ & $\begin{array}{l}\text { 2. Positive SARS-CoV-2 test for current or recent } \\
\text { infection by Real Time-PCR, serology or antigen } \\
\text { detection }\end{array}$ \\
\hline & 2. Rash and conjunctivitis without purulence & \\
\hline & Secondary clinical criteria & \\
\hline & $\begin{array}{l}\text { 1. New neurologic signs and symptoms, including peripheral } \\
\text { neuropathy, seizures, meningeal signs or new-onset encephalopathy }\end{array}$ & \\
\hline & 2. New shock or hypotension & \\
\hline & 3. Diarrhoea, abdominal pain or emesis & \\
\hline & 4. Thrombocytopenia (platelet count: $<150000 / \mu \mathrm{L}$ ) & \\
\hline
\end{tabular}

*The date of hospital admission is hospital day 0.

CDC, Centers for Disease Control; CRP, C reactive protein; IL-6, interleukin 6; LVEF, left ventricular ejection fraction; MIS-A, multisystem inflammatory syndrome in adults.

In previous COVID-19 outbreaks, an overactive antibodymediated response has also been described. ${ }^{11}$ Our patient had sustained elevated inflammatory markers several days into his clinical course (figure 2). Endomyocardial biopsy in our patient showed evidence of catecholamine-induced myocardial injury. A scant lymphocytic infiltrate has been described in COVID-19 myocarditis, ${ }^{7}$ while in this case the infiltrate consisted of neutrophils and eosinophils.

Currently, there are no evidence-based recommendations for the treatment of MIS-A. However, The American College of Rheumatology has published recommendations for management of MIS-C. ${ }^{12}$ These include the immunomodulatory agents, intravenous Ig and glucocorticoids, as the first-line treatment for patients with life-threatening manifestations of MIS-C. Given that MIS-A shares a similar pathophysiologic mechanism to MIS-C, glucocorticoids and intravenous Ig are also being recommended as a first-line treatment in case reports. ${ }^{13}$

Our case further supports the use of advanced mechanical circulatory support devices such as Impella and VA-ECMO in patients with cardiogenic shock from MIS-A. Even in relatively

\section{Patient's perspective}

I didn't even know that I had had a recent COVID-19 infection, or that my heart was weak. I initially went to the hospital due to this cough that I had developed. Then the doctor told me that my heart was weak, and I had a recent COVID-19 infection due to my positive antibodies.

When they told me that my heart was weak, I was devastated and couldn't believe it. When they told me I needed a small procedure, I was shocked. A lot of people are sick and they don't even know it.

After the [ECMO] procedure when I was in the ICU, I have no recollection. I have no memory of that time. All I know is that I thank the doctors for what they did, and everyone who prayed for me. I also want to thank everyone who prayed for me.

Right now I'm not feeling too bad. Occasionally I feel short of breath. Like if I'm climbing up a staircase, sometimes I feel a little short of breath. Otherwise, I'm not doing too bad. older patients such as ours, VA-ECMO and Impella support can be used to improve haemodynamics and allow for complete recovery of left ventricle function.

\section{Learning points}

- Multisystem inflammatory syndrome in adults (MIS-A) can present with cardiogenic shock and associated haemodynamic collapse.

- Combined mechanical circulatory support with venoarterial extracorporeal membrane oxygenation and Impella may be necessary for treatment of MIS-A.

- Endomyocardial biopsy may play a useful role in differentiating cardiogenic shock from myocarditis and MIS-A.

Acknowledgements We would like to acknowledge Yogita Rochlani, Daniel Schwartz, Stephen Forest and Mayuko Uehara for their contribution to the care of this patient.

Contributors The patient was under the direct care of all of the authors, including DS, SM, FZ and SN. All authors were involved in the conception and design of the case report, acquisition and analysis of the data, interpretation of the data, drafting and revising of the case report, final approval of the version to be published and are in agreement to be accountable for the article and to ensure that all questions regarding the accuracy or integrity of the article are investigated and resolved.

Funding The authors have not declared a specific grant for this research from any funding agency in the public, commercial or not-for-profit sectors.

Competing interests None declared.

Patient consent for publication Consent obtained directly from patient(s).

Provenance and peer review Not commissioned; externally peer reviewed.

Case reports provide a valuable learning resource for the scientific community and can indicate areas of interest for future research. They should not be used in isolation to guide treatment choices or public health policy.

\section{REFERENCES}

1 Feldstein LR, Rose EB, Horwitz SM, et al. Multisystem inflammatory syndrome in U.S. children and adolescents. N Eng/ J Med 2020;383:334-46.

2 Morris SB, Schwartz NG, Patel P, et al. Case Series of Multisystem Inflammatory Syndrome in Adults Associated with SARS-CoV-2 Infection - United Kingdom and United States, March-August 2020. MMWR Morb Mortal Wkly Rep 2020;69:1450-6. 
3 Newman SB. Audio file of patient consent [sound recording]. Created October 13, 2021.

4 CDC.gov [internet]. Multisystem inflammatory syndrome in adults (MIS-A) case definition information for healthcare providers. Available: https:/www.cdc.gov/mis/ mis-a/hcp.html [Accessed 31 Dec 2021].

5 Bastug A, Aslaner H, Aybar Bilir Y, et al. Multiple system inflammatory syndrome associated with SARS-CoV-2 infection in an adult and an adolescent. Rheumatol Int 2021:41:993-1008.

6 Hajra K, Chakraborty U, Chatterjee K, et al. Multisystem inflammatory syndrome in adults (MIS-A): a new addition to COVID-19 puzzle. J Eur Acad Dermatol Venereol 2022;36:e182-5.

7 Salamanca J, Díez-Villanueva P, Martínez P, et al. COVID-19 "Fulminant Myocarditis" Successfully Treated With Temporary Mechanical Circulatory Support. JACC Cardiovasc Imaging 2020;13:2457-9.

8 Papageorgiou J-M, Almroth H, Törnudd M, et al. Fulminant myocarditis in a COVID-19 positive patient treated with mechanical circulatory support - a case report. Eur Heart J Case Rep 2021;5:ytaa523.
9 Bemtgen $X$, Krüger K, Supady A, et al. First successful treatment of coronavirus disease 2019 induced refractory cardiogenic plus Vasoplegic shock by combination of percutaneous ventricular assist device and extracorporeal membrane oxygenation: a case report. Asaio J 2020;66:607-9.

10 Veyseh M, Webster P, Blanco I. COVID-19-associated inflammatory syndrome in an adult woman with unexplained multiple organ failure: staying vigilant for COVID-19 complications as the pandemic surges. BMJ Case Rep 2021;14:e242034.

11 Wang S-F, Tseng S-P, Yen C-H, et al. Antibody-dependent SARS coronavirus infection is mediated by antibodies against spike proteins. Biochem Biophys Res Commun 2014:451:208-14.

12 Henderson LA, Canna SW, Friedman KG, et al. American College of rheumatology clinical guidance for multisystem inflammatory syndrome in children associated with SARS-CoV-2 and Hyperinflammation in pediatric COVID-19: version 1. Arthritis Rheumatol 2020;72:1791-805.

13 Ahmad F, Ahmed A, Rajendraprasad SS, et al. Multisystem inflammatory syndrome in adults: a rare sequela of SARS-CoV-2 infection. Int J Infect Dis 2021:108:209-11.

Copyright 2022 BMJ Publishing Group. All rights reserved. For permission to reuse any of this content visit https://www.bmj.com/company/products-services/rights-and-licensing/permissions/

BMJ Case Report Fellows may re-use this article for personal use and teaching without any further permission

Become a Fellow of BMJ Case Reports today and you can:

- Submit as many cases as you like

- Enjoy fast sympathetic peer review and rapid publication of accepted articles

- Access all the published articles

- Re-use any of the published material for personal use and teaching without further permission

\section{Customer Service}

If you have any further queries about your subscription, please contact our customer services team on +44 (0) 2071111105 or via email at support@bmj.com. Visit casereports.bmj.com for more articles like this and to become a Fellow 